\title{
MIR193A Pre-miRNA
}

National Cancer Institute

\section{Source}

National Cancer Institute. MIR193A Pre-miRNA. NCI Thesaurus. Code C82790.

MIR193A is an olig oribonucleotide that is encoded by the human MIR193A gene and has a role in the regulation of gene expression. 